\title{
Hepatitis B Virus, Hepatitis C Virus Markers and Serum Alanine Amino-Transferase (ALT) Levels, in a Young Adult Population of Sylhet District
}

\author{
I PERVEEN $^{\mathrm{a}}$, M SAHA $^{\mathrm{b}}, \mathrm{KK} \mathrm{DHAR}^{\mathrm{c}}$, MS ISLAM $^{\mathrm{d}}$
}

\begin{abstract}
Summary:
Objective: To find out the seroprevalence of the hepatitis $B$ and $C$ viruses in a young adult population along with estimation of aminotransferase levels. And so as to increase the awareness and augment preventive measures against these viral hepatitis related morbidity.
\end{abstract}

Methods: A total of 2611 apparently healthy young adults were screened from January 2010 to December 2010 at a Medical Checkup center of Sylhet for hepatitis B surface antigen (HBsAg), hepatitis C virus antibody (anti HCV), alanine aminotransferase (ALT) and aspertate aminotransferase (AST) levels.

Results: Out of 2611 subjects 2536(97.1\%) were male and $75(2.9 \%)$ were female with comparable mean ages $(29.08 \mathrm{vs}$. 30.6 years, $P$.056). A total of 77(3.0\%) men were $\mathrm{HBs} \mathrm{Ag}$ positive and only four $(0.16 \%)$ men were positive for anti

Introduction:

Chronic hepatitis B virus (HBV) and hepatitis $\mathrm{C}$ virus (HCV) infections are global challanges. Globally 350 million people are suffering from chronic (lifelong) infections and more than one million people die each year from liver cirrhosis and liver cancer ${ }^{1}$. In the Middle East and Indian sub-continent, HBV infection is of intermediate endemicity with chronic $\mathrm{HBV}$ carriage rate of $2-5 \%$ among general population ${ }^{1}$. In Bangladesh, there is paucity of information on the prevalence of $\mathrm{HBV}$ infections. According to a recent report hepatitis

a. Irin Perveen, Associate Professor of Gastroenterology, Enam Medical College, Dhaka, Bangladesh

b. Madhusudan Saha, Associate Professor of Gastroenterology, North East Medical College, Sylhet, Bangladesh.

c. Kishore Kumar Dhar, Internee Doctor, North East Medical College, Sylhet, Bangladesh.

d. Md Shamsul Islam, Registrar of Medicine, North East Medical College, Sylhet, Bangladesh.

Address of Correspondence: Irin Perveen, B-11, Tropical kader Garden, 335 Tongi Diversion Road, Bara Magh Bazar, Dhaka-1217, Bangladesh. Phone numbers: +8801552365100 , E-mail address: irinperveen@yahoo.com,

Received: 25 July 2015

Accepted: 28 September 2016
HCV. Women were all negative for HBsAg or anti $\mathrm{HCV}$. None had co-infection with $\mathrm{HBV}$ and HCV. Mean ALT and AST levels of study population were 31.85 I.U./L and 26.18 I. $U . / L$ respectively and were not found to vary with age and sex. Mean ALT levels were more in in HBsAg positive cases (42.03 I.U/L vs. 31.5 I.U./L, P.000) and HCV infected cases (49 I.U./L vs. 31.51 I.U./L, P.000) than non-infected persons.

Conclusion: Hepatitis $B$ infection is of intermediate endemicity among young adults while hepatitis $C$ virus infection is low among this group. Mean amino transferase levels were higher in asymptomatic infected persons in comparison to non-infected person. We suggest the need for revision of upper limit of normal for ALT in our population for early detection and treatment of liver diseases.

Key Words: Hepatitis $B$ virus, hepatitis $C$ virus, alanine amino-transferase, young adults.

(J Bangladesh Coll Phys Surg 2016; 34: 199-205)

B surface antigen (HBsAg) positivity was 5.5\% among the general population of a semi-urban area near Dhaka city $^{2}$. The reported prevalence of HBsAg in selected population of Bangladesh ranges between 2-3.5\% $\%^{3-5}$. The prevalence is much higher in high risk group ${ }^{6-9}$.

According to World Health Organization (WHO), 130170 million persons are chronically infected worldwide with hepatitis $\mathrm{C}$ virus (HCV). ${ }^{10}$ Approximately $10 \%$ to $20 \%$ of chronic $\mathrm{HCV}$ infection cases, will progress to cirrhosis and hepatocellular carcinoma. ${ }^{10}$. The highest prevalence rates are reported from developing poor countries from Africa and Asia. Estimates of HCV prevalence in Southeast Asian countries are $2.0 \%$ to $3.8 \%{ }^{11,12}$ for the general population, $12.5 \%$ for patients with chronic liver disease ${ }^{13}$, and more than $90 \%$ for injecting drug users ${ }^{14}$. Currently, there is limited information on the HCV prevalence and risk factors in the general population of Bangladesh. The reported seroprevalence of $\mathrm{HCV}$ among people of an impoverished area of Bangladesh ${ }^{15}$, rural area, ${ }^{16}$ healthy blood donors ${ }^{3}$ and drug addicts ${ }^{17}$ were $0.2 \%, 0.6 \%, 0.25 \%$ and $15.0 \%$ respectively.

Serum alanine aminotransferase (ALT) concentration is the most widely used sensitive and reliable marker of 
liver diseases. Several population-based studies have found slightly increased ALT levels within the current normal range to be closely related to comorbidities and mortality. ${ }^{18-20}$ Current upper limit of normal (ULN) for ALT level were set, on average, ranging from $30 \mathrm{U} / \mathrm{L}$ to $50 \mathrm{U} / \mathrm{L}$ over the past 10 years. Such thresholds, however, vary tremendously among hospitals, research centers and geographic locations. The normal range of serum ALT for any laboratory test is the mean value plus two standard deviations in a supposedly healthy reference population, and the upper limit of normal (ULN) is established statistically as the value at the 97.5 th percentile. ${ }^{21}$ Currently, several studies have been reevaluated the ULN ALT in different countries by involving different age groups. And the recommended ULN ALT was $30 \mathrm{U} / \mathrm{L}$ for men and $19 \mathrm{U} / \mathrm{L}$ for women respectively. ${ }^{18,22-24}$ Based on the previous results it is found that, recent ULNALT greatly increase the number of asymptomatic patients with abnormal ALT values, and would identify more patients with nonalcoholic fatty liver disease (NAFLD) and clinically mild HBV/HCV infection.

We have no data regarding the upper limit of normal for ALT in our population. Most of the laboratories follow the manufacturer's recommendation (40 - 65 I.U./L) for a particular analyzer to establish ULNALT without healthy volunteer testing. It is evident that $\mathrm{HBV}$ and $\mathrm{HCV}$ infections are rapidly spreading in developing countries due to the lack of health education, poverty, illiteracy and lack or cost of proper vaccination. As many chronically infected individuals remain asymptomatic, and thus undetected for many years, we planned this serological study to determine the seroprevalence of HBsAg and anti-HCV and to estimate corresponding serum ALT levels among a group of apparently healthy people coming for medical checkup for the purpose of jobs in the Middle East. We hoped that the findings might guide eventually the development, adaptation, and evaluation of management strategies.

\section{Methodology}

Hepatitis C virus (HCV) and hepatitis B virus (HBV) seroprevalence study was undertaken among 2611 subjects coming for medical checkup in one of three referrence centers of Sylhet district. All were young adults applying for job visas to different Middle East countries. Data were collected by the trained staff from the medical center over a period of 10 months, September 2011 to June 2002 and were recorded in the registry book of the medical centre. Physical examination and laboratory investigations including markers for several infectious diseases and drugs of abuse were carried out as required by the countries recruiting the workers. Consents were taken for blood tests Immediately following the interview, a 10-mL aliquot of blood was drawn from each participant to test for hepatitis $B$ surface antigen (HBsAg), anti- $\mathrm{HCV}$ and serum alanine amnotranserase (ALT) and aspertate amno-transerase (AST) levels.

\section{Data analysis}

Data were analyzed using the SPSS version 20.0 statistical program. Prevalence estimates of cases positive for HBsAg and anti-HCV were stratified by demographic characteristics. A $\div 2$ test was used for comparisons between proportions, while Students $t$ test was used for comparisons of means, with á set at the $5 \%$ level.

\section{Ethics}

Participation was voluntary and informed consent for interviewing and blood tests was obtained. Participants who tested positive for $\mathrm{HBsAg}$ or anti-HCV were offered posttest counseling by specialists. The study protocol was approved by the Ethics Committee of Northeast Medical College of Sylhet, Bangladesh.

\section{Result:}

Out of 2614 participants, 3 cases were excluded for very high level (> 1000 I.U./L) of SGPT and SGOT level. One of them had bilirubin level $7.30 \mathrm{mg} / \mathrm{dl}$. Viral markers were negative in all three subjects.

Among the remaining 2611 subjects, 2536(97.1\%) were male and $75(2.9 \%)$ were female with comparable mean ages (29.08 \pm 6.767 vs. $30.6 \pm 7.600$, P .056). Out of this study population, 77(3.0\%) male were HBsAg positive while none of the women were HBsAg positive. Study population mostly belonged to 21-40 years group $(\mathrm{n}=2351,90.0 \%)$ and HBsAg positivity among this group were $2.85 \%(\mathrm{n}=67)$ (table 2$)$. Only four men $(0.16 \%)$ were positive for anti $\mathrm{HCV}$ and women were all negative for anti HCV. None had co-infection with HBV and HCV.

Mean ALT and AST levels of study population were 31.85 I.U./L(range, 17-226 I.U./L) and 26.18 I.U./L(range ,14- 211 I.U./L) respectively and mean values were 8.15 unit and 13.82 unit lower than upper level of normal values(40 I.U./L). No significant difference was noted in these enzyme levels in males and females (table 1). No significant difference was noted in ALT and AST 
levels in more than 40 years and less than 40 years group (table 2). Mean bilirubin level of study population was $0.667 \pm .258 \mathrm{mg} / \mathrm{dl}$ (range $.10-7.30 \mathrm{mg} / \mathrm{dl}$ ). No significant difference was noted in the mean bilirubin level in HBV and HCV infected persons than noninfected persons (table 3 and 4)

ALT levels more than 40units/L was found in 107 cases; among them 78 cases (3.1\%) were both HBSAg and anti HCV negative while 26 cases $(33.8 \%)$ were $\mathrm{HBsAg}$ positive ( $\mathrm{P} 0.000)$ and $3(75.0 \%)$ were anti $\mathrm{HCV}$ positive. ALT level more than 30 I.U. was found in $77.4 \%(n=55)$ of $\mathrm{HBsAg}$ positive males while In anti HCV positive males all 4 had ALT more than 30 I.U./L. In female ALT level $>19$ was found in $98.7 \%(\mathrm{n}=74)$ and in $96.0 \%(\mathrm{n}=72)$ ALT was less than 40 I.U./L. Similarly AST levels more than 40 I.U./L was found in $2.3 \%(\mathrm{n}=58)$ non-infected subjects and in $22.0 \%(\mathrm{n}=17)$ of $\mathrm{HBsAg}$ positive cases( $\mathrm{P} 0.000)$.

Mean ALT and AST levels were significantly more in in HBsAg positive cases than HBsAg negative cases (table3). These two levels were also significantly more in anti $\mathrm{HCV}$ positive cases than anti $\mathrm{HCV}$ negative cases (table 4). The ALT and AST values in HBsAg and anti $\mathrm{HCV}$ negative subjects $(\mathrm{n}=2530)$ at 97.5 th percentile were 49 I.U./L and 40I.U./L respectively.

Table-I

\begin{tabular}{lccc} 
& \multicolumn{4}{c}{ Liver function test profile according to sex } & \\
& Male & Female & P-value \\
& $\mathrm{N}=2536$ & $\mathrm{~N}=75$ & \\
\hline HBsAg positive & $77(3.0 \%)$ & 0 & .171 \\
Anti HCV positive & $4(0.16 \%)$ & 0 & $\mathrm{~N} \mathrm{~S}$ \\
Mean ALT & $31.9 \pm 12.4 \mathrm{I} . \mathrm{U} . / \mathrm{L}$ & $29.4 \pm 7.2 \mathrm{I} . \mathrm{U} . / \mathrm{L}$ & 0.073 \\
Mean AST & $26.2 \pm 10.4 \mathrm{I} . \mathrm{U} / \mathrm{L}$ & $24.1 \pm 5.9 \mathrm{I} . \mathrm{U} . / \mathrm{L}$ & .077 \\
Mean bilirubin & $.67 \pm .23 \mathrm{mg} / \mathrm{dl}$ & $.58 \pm .15 \mathrm{mg} / \mathrm{dl}$ & 0.001 \\
\hline
\end{tabular}

Table-II

Liver function tests according to age category

Age category

HBsAg positive

$<20$ years $(\mathrm{n}=48)$

$21-40$ years $(\mathrm{n}=2351)$

$>40$ years $(n=212)$

Anti HCV positive

$<20$ years $(\mathrm{n}=48)$

$21-40$ years $(n=2351)$

$>40$ years $(n=212)$

Mean ALT level

$<20$ years $(\mathrm{n}=48)$

$21-40$ years $(\mathrm{n}=2351)$

$>40$ years $(n=212)$

Mean AST level

$<20$ years $(\mathrm{n}=48)$

$21-40$ years $(n=2351)$

$>40$ years $(n=212)$

Mean bilirubin level

$<20$ years $(\mathrm{n}=48)$

$21-40$ years $(n=2351)$

$>40$ years $(n=212)$
P-value

0.482

$1(2.08 \%)$

$67(2.85 \%)$

$9(4.3 \%)$

0

0.453

$3(.13 \%)$

$1(.47 \%)$

$29.3 \pm 7.7 \mathrm{I} . \mathrm{U} / \mathrm{L}$

0.331

$31.9 \pm 12.5$ I.U/L

$31.7 \pm 10.3$ I.U/L

$23.96 \pm 6.8$ I.U/L

0.248

$26.3 \pm 10.5$ I.U/L

$25.7 \pm 8.1$ I.U/L

$.78 \pm .44 \mathrm{mg} / \mathrm{dl}$

0.007

$.67 \pm .26 \mathrm{mg} / \mathrm{dl}$

$.65 \pm .19 \mathrm{mg} / \mathrm{dl}$ 


\section{Table-III}

\begin{tabular}{lccc}
\multicolumn{4}{c}{ Mean bilirubin, mean ALT and mean AST levels in HBsAg positive subjects } \\
& HBsAg positive & HBsAg \& Anti HCV negative & P-value \\
& $\mathrm{N}=77$ & $\mathrm{~N}=2530$ & \\
\hline Mean Bilirubin(mg/dl) & $.72 \pm .25$ & $.67 \pm .26$ & .084 \\
Mean ALT(I.U./L) & $42.0 \pm 17.3$ & $31.5 \pm 11.9$ & .000 \\
Mean AST(I.U./L) & $34.3 \pm 13.96$ & $25.9 \pm 10.0$ & .000 \\
\hline
\end{tabular}

\section{Table-IV}

Mean bilirubin, mean ALT and mean AST levels in Anti HCV positive subjects

\begin{tabular}{|c|c|c|c|}
\hline & $\begin{array}{l}\text { Anti } \mathrm{HCV} \\
\text { positive } \\
\mathrm{N}=4\end{array}$ & $\begin{array}{c}\text { HBsAg \& Anti HCV } \\
\text { negative } \\
\mathrm{N}=2530\end{array}$ & P-value \\
\hline$\overline{\text { Mean Bilirubin (mg/dl) }}$ & $.53 \pm .05$ & $.67 \pm .26$ & .271 \\
\hline Mean ALT(I.U./L) & $49.0 \pm 14.9$ & $31.5 \pm 11.9$ & .000 \\
\hline Mean AST( I.U./L) & $40.0 \pm 11.78$ & $25.9 \pm 10.05$ & .000 \\
\hline
\end{tabular}

\section{Discussion:}

HBsAg is the most reliable biological biomarker of chronic HBV infection, and the antibody against hepatitis B core antigen (anti-HBc) is an important marker for surveying the burden of HBV infection for identifying both past and current HBV infection. ${ }^{25}$ Thirty years ago Islam et al. in 1984, reported a seroprevalence 7.8\% of HBsAG among apparently healthy workers applied for jobs in foreign countries. ${ }^{26}$ Thirty years later we found a seroprevalence of $2.95 \%$, which corresponds to the findings of Rumi et al, ${ }^{27}$ who reported a prevalence of $4.4 \%$ among healthy workers.

The HBsAg prevalence of $2.95 \%$ among our study population corresponds to the range of $2-7 \%$ reported by previous studies from the selected population: $2 \%$ among healthy blood doners ${ }^{3}, 3 \%$ among healthy adults and children ${ }^{4}$ and $3.5 \%$ among pregnant women. ${ }^{5}$ The prevalence also corresponds to reports among highrisk group: $8.0 \%$ among drug addicts, ${ }^{8} 5.9 \%$ among truck drivers and helpers. ${ }^{28}$ Lack of proper health care, lower socioeconomic status, less public awareness about the HBV transmission and lack of vaccination are proposed reason for high prevalence of HBV. High prevalence also reported in other high risk groups of Dhaka: 7.6\% among women at a sexually transmitted disease (STD) clinic $^{9}, 8 \%$ among intravenous drug users (IDUs) $)^{8}, 8.6 \%$ among surgically operated patients, ${ }^{6} \quad 9.7 \%$ among commercial sex workers(CSWs), ${ }^{7} 19 \%$ among hepatitis patients $^{29}$; and $47 \%$ among hepatocellular carcinoma. ${ }^{30}$

The estimates of HBV exposures were far higher when anti $\mathrm{HBc}$ was used as marker for $\mathrm{HBV}$ infection among urban slum $(22.6 \%),{ }^{15}$ drug addicts $(27.8 \%){ }^{17}$ and healthy adults and children $(21.1 \%)^{4}$. Anti HBc positivity was much higher in the high-risk groups of Dhaka: $24.1 \%$ in non-IDUs and $31.8 \%$ in IDUs ${ }^{17} ; 35.2 \%$ among women at a STD clinic ${ }^{9} ; 48.1 \%$ among truck drivers and helpers, ${ }^{28} 49.3 \%$ among women living near a truck stand, ${ }^{31}$ and $73 \%$ among CSWs.$^{7}$ The apparently low prevalence of $\mathrm{HBV}$ infection in the present study may be due to use of single marker or may reflect the true low prevalence among non-vulnerable population.

The $0.15 \%$ prevalence of anti-HCV observed in our study population is lower than that reported from highrisk groups of Dhaka: $0.8 \%$ among truck drivers and helpers, ${ }^{28} 0.9 \%$ among women at a STD clinic, ${ }^{9} 1.6 \%$ among women living near a truck stand, ${ }^{31} ; 5.8 \%$ in nonIDUs and $24.8 \%$ in IDUs, ${ }^{17}$ and $13 \%$ among hepatitis patients. ${ }^{29}$ The report corresponds to the findings of Ashraf et al. where seroprevalence among population of an impoverished area were $.2 \% .{ }^{15}$ Our results of Ant $\mathrm{HCV}$ prevalence was much lower than other South Asian countries. ${ }^{11,12}$ As HCV infection is rare, and as a 
consequence co-infection with $\mathrm{HBV}$ and $\mathrm{HCV}$ is much rarer in our subjects. In the context of the absence of an $\mathrm{HCV}$ vaccine and the prohibitive cost of $\mathrm{HCV}$ treatment for the vast majority of the world's HCV-infected population, identification and elimination of risk factors for $\mathrm{HCV}$ remains the only option for reduction of $\mathrm{HCV}$ related disease burden for most developing economies.

ALT is a good indicator of health and meets most of the accepted criteria for a screening test. ${ }^{32}$. Current upper limit of normal (ULN) for ALT levels (30-50I.U./L)were set based on the studies conducted prior to the introduction of hepatitis $\mathrm{C}$ virus( $\mathrm{HCV})$ testing and prior to the development of concept of nonalcoholic fatty liver disease(NAFLD). For a number of reason researchers support the lowering the ULN to achieve appropriate screening and medical attention for patients with borderline ALT levels. First, screening using the past range of normal serum ALT values might underestimate the prevalence of CLD. Second, considering the natural courses of NAFLD or chronic $\mathrm{HBV} / \mathrm{HCV}$ infections, disease progression with significant degrees of necroinflammatory activity and fibrosis of liver might occur in patients with persistently normal ALT levels. ${ }^{27-31}$ According to current guidelines, antiviral therapy should be initiated with evidence of viral replication in all patients with serum ALT levels more than twice the ULN and in selected patients with serum ALT levels one to two times the ULN. ${ }^{27,} 35$ Adjustment of the ULN by defining borderline ALT levels as abnormal would allow more vigorous surveillance and earlier initiation of treatment. Third, Consistent with this finding, borderline rise of ALT values are early indicators of co-morbidities associated with lifestyle and with liver injury due to hepatic steatosis. ${ }^{37}$

In the present series mean ALT level was 31.93 I.U./L (range17-226 I.U./L). It was not found to vary significantly with age (P 0.331) and sex (P .073). Mean ALT level in HBsAg positive subjects was significantly more than in HBsAg negative subjects (P .000)(table 3). When ULN ALT was considered as 40I.U./L only 33\% HBsAg positive subjects were found to have raised ALT, but when upper level was lowered to 30 I.U./L, $71.4 \%$ HBsAg positive subjects were found to have abnormal ALT values. In case of hepatitis $\mathrm{C}$ infection this percentages raised to $100 \%$ from $75.0 \%$. From our study results it is apparent that with currently adopted ALT values a good number of $\mathrm{HBV}$ and $\mathrm{HCV}$ infected patients remained outside the scope of antiviral treatment and these patients may inadvertently exposed to many hepatotoxic medications.

We cannot comment on healthy ULN ALT as other diseases like NAFLD and metabolic disorders were not excluded by ultrasonography/MRI, liver biopsy and other relevant tests. But when HBV, HCV infection cases were excluded, at $97.5^{\text {th }}$ percentile ALT level was 49 I.U/ L. this level is higher than recently recommended ULN ALT. ${ }^{22-24}$

There are some limitations of our study. First, we did not perform some diagnostic tests for HBV, e.g. anti-HBc IgM, the presence of which indicates acute infection; and antiHBs that differentiates susceptible persons from those immune persons, which can be due either to natural infection or hepatitis B vaccination. Second, we did not perform some diagnostic tests for $\mathrm{HCV}$, e. g. recombinant immunoblot assay (RIBA) to confirm $\mathrm{HCV}$ exposure, or polymerase chain reaction (PCR) to detect $\mathrm{HCV}$ infected individuals. All the above limitations are mainly due to study cost constraints, mostly related to laboratory tests. The third limitation is that the familial clustering effects of hepatitis viruses, and risk factors for acquisition of viral hepatitis were not assessed. The fourth limitation is that the study was conducted in a selected population of Sylhet district, and may not reflect all of Bangladesh. A final limitation is the relatively short observation window, which may have missed important secular trends in the background prevalence of both the hepatitis $\mathrm{B}$ and $\mathrm{C}$ viruses.

\section{Conclusions:}

The results of our study indicate an intermediate level of endemicity of HBV infection as $2.95 \%$ our valuable young adult population were HBsAg positive. However, we observed a much lower prevalence of $\mathrm{HCV}$ infections in the same community. We hope that this endemic presence of HBV virus, would make awareness among our health care providers and policy makers in designing and implementing effective preventive programmes. The findings also highlighted the need for prevention and control of HBV and HCV infections in Bangladesh by implementing universal hepatitis $B$ vaccination and creating public awareness to prevent viral transmission. We suggest the need for revision of Upper Limit of Normal for ALT in our population for early detection and initiation of treatment of liver diseases. 
Long-term population-based surveillance studies, with extended HBV serology, are needed for more accurate assessment of the hepatitis $\mathrm{B}$ and hepatitis $\mathrm{C}$ disease burden in our country, the impact of vaccination, and to guide prioritization of limited health care resources. Further studies are also required to confirm the familial clustering effect, for exploring transmission dynamics and to identify risk factors for viral hepatitis.

\section{Acknowledgements}

We acknowledge with gratitude the commitment of the Popular Medical Checkup Centre, Sylhet which provide unrestricted support to the present research efforts. The authors are grateful to Dr. Mahbubur Rahman and Khalequzzaman for their excellent review of the manuscript.

\section{References:}

1. Hepatitis B [http:// www. who. int/ mediacentre/ factsheets/ fs204/ en] 2008.

2. Mahtab MA, Rahman S, Karim MF, Khan M, Foster G, Solaiman S, et al. Epidemiology of hepatitis B virus in Bangladeshi general population. Hepatobiliary Pancreat Dis Int 2008, 7: 595-600.

3. Saha SK, Banik RK, Saha MR, Habibullah MM, MamunAl-Mahtab. Prevalence of Transfusion Transmitted Infection in Healthy Blood Donors in Sir Salimullah Medical College Dhaka, Bangladesh. Euroasian Journal of Hepato- Gastroenterology 2011;1: 68-70. DOI 10.5005/ jp-journals-10018-1015

4. Zaki H, Darmstadt GL, Baten A, Ahsan CR, Saha SK. Seroepidemiology of hepatitis B and delta virus infections in Bangladesh. J Trop Pediatr 2003, 49: 371-4.

5. Rumi MA, Begum K, Hassan MS, Hasan SM, Azam MG, Hasan KN, et al. Detection of hepatitis B surface antigen in pregnant women attending a public hospital for delivery: implication for vaccination strategy in Bangladesh. Am J Trop Med Hyg 1998, 59: 318-22.

6. Ahmad Q, Chowdhury SG, Islam MN, Khan FD, Alam MR, Miah AH. HBsAg amongst unscreened operated patients. Bangladesh Med Res Counc Bull 1991, 17: $11-6$.

7. Sattar H, Islam MN. Hepatitis B virus markers among the prostitutes of Dhaka. Bangladesh Med Res Counc Bull 1996, 22: 8-11.

8. Mustafa M, Islam MN, Rahman M, Salauddin AK. Prevalence of hepatitis B surface antigen (HBsAg) among parenteral drug abusers at Dhaka. Bangladesh Med Res Counc Bull 1989, 15: 1-7.
9. Bogaerts J, Ahmed J, Akter N, Begum N, Rahman M, Nahar S, et al. Sexually transmitted infections among married women in Dhaka, Bangladesh: unexpected high prevalence of hetpes simplex type 2 infection. Sex Transm Infect 2001;77: 114-9.

10. Hepatitis C. [http://www.who.int/mediacentre/factsheets/ fs164/en/] 2000. Accessed November 25, 2006

11. Ratanasuwan W, Sonji A, Tiengrim S, Techasathit W, Suwanagool S. Serological survey of viral hepatitis A, B, and $\mathrm{C}$ at Thai Central Region and Bangkok: a population base study. Southeast Asian J Trop Med Public Health 2004;35:416-420]

12. Ishida T, Takao S, Settheetham-Ishida W, Tiwawech D. Prevalence of hepatitis $\mathrm{B}$ and $\mathrm{C}$ virus infection in rural ethnic populations of Northern Thailand. J Clin Virol 2002; 24:31-35.]

13. Pramoolsinsap C, Sumalnop K, Busagorn N, Kurathong S. Prevalence and outcomes of $\mathrm{HBV}$ and anti-HCV seropositive patients with chronic liver disease and hepatocellular carcinoma. Southeast Asian J Trop Med Public Health 1992; 23: 6-11.

14. Luksamijarulkul P, Plucktaweesak S. High hepatitis C seroprevalence in Thai intravenous drug abusers and qualitative risk analysis. Southeast Asian J Trop Med Public Health 1996; 27:654-658.

15. Ashraf H, Alam NH, Rothermundt C, Brooks A, Bardhan $\mathrm{P}$, Hossain L, et al. Prevalence and risk factors for hepatitis $\mathrm{B}$ and $\mathrm{C}$ virus infections in an impoverished urban community in Dhaka, Bangladesh. BMC Infectious Diseases 2010; 208, DOI: 10.1186/1471-2334-10-208

16. Safiullah ABM, Bhuiyan MMR, Miah MAR and Raihan ASMA. Prevalence of hepatitis $C$ virus infection in rural adult population of Bangladesh. Bangladesh Med Res Counc Bull 2009, 35: 30-32.

17. Shirin T, Ahmed T, Iqbal A, Islam I, Islam N. Prevalence and risk factors of hepatitis $\mathrm{B}$ virus, hepatitis $\mathrm{C}$ virus and human immunodeficiency virus infections among drug addicts of Bangladesh. J Health Popul Nutr 2000; 18(3): 145-150.

18. Kim HC, Nam CM, Jee SH, Han KH, Oh DK, Suh II. Normal serum aminotransferase concentration and risk of mortality from liver diseases: prospective cohort study. BMJ 2004:328: 983. doi: 10.1136/bmj.38050.593634.63

19. Kang HS, Um SH, Seo YS, An H, Lee KG, Hyun JJ, et al. Healthy range for serum ALT and the clinical significance of "unhealthy" normal ALT levels in the Korean population. J. Gastroenterol. Hepatol. 2011; 26: 292-9.

20. Chang Y, Ryu S, Sung E, Jang Y. Higher concentrations of alanine aminotransferase within the reference interval predict nonalcoholic fatty liver disease. Clin. Chem. 2007; 53: $686-92$. 
21. Pratt DS, Kaplan MM. Evaluation of abnormal liverenzyme results in asymptomatic patients. N Engl J Med 2000; 342: 1266-71.

22. Schwimmer JB, Dunn W, Norman GJ, Pardee PE, Middleton MS, et al. SAFETY study: alanine aminotransferase cutoff values are set too high for reliable detection of pediatric chronic liver disease. Gastroenterology 2010;138: 1357-1364, 1364 e 13511352. doi: $10.1053 /$ j.gastro.2009.12.052

23. Van der Poorten D, Kenny DT, Butler T, George J. Liver disease in adolescents: a cohort study of high-risk individuals. Hepatology 2007; 46: 1750-1758. doi: 10.1002/hep. 21918

24. Prati D, Taioli E, Zanella A, Della Torre E, Butelli S, Del Vecchio $\mathrm{E}$ et al. Updated definitions of healthy ranges for serum alanine aminotransferase levels. Ann Intern Med 2002;137: 1-10.

25. Deinhartd F. Serum markers of hepatitis viruses in natural disease and after vaccination. Prog Liver Dis 1982, 7: 451-67.

26. Islam MN, Islam KM, Islam N. Hepatitis-B virus infection in Dhaka, Bangladesh. Bangladesh Med Res Counc Bull 1984, 10: 1-6.

27. Rumi MA, Siddiqui MA, Salam MA, Iqbal MR, Azam MG, Chowdhury AK, et al. Prevalence of infectious diseases and drug abuse among Bangladeshi workers. Southeast Asian J Trop Med Public Health 2000, 31: 571-4.

28. Gibney L, Saquib N, Metzger J, Choudhury P, Siddiqui M, Hassan M. Human immunodeficiency virus, hepatitis B, $\mathrm{C}$ and D in Bangladesh's trucking industry: prevalence and risk factors. Int J Epidemiol 2001, 30: 878-84.

29. Khan WI, Sultana R, Rahman M, Akhter H, Haq JA, Ali L, et al. Viral hepatitis: recent experiences from serological studies in Bangladesh. Asian Pac J Allergy Immunol 2000, 18: 99-103.
30. Khan M, Haq S, Ahmed N, Matin MA. Etiology and clinical profile of hepatocellular carcinoma in Bangladesh. Bangladesh Med Res Counc Bull 1997; 23: 16-24.

31. Gibney L, Macaluso M, Kirk K, Hassan MS, Schwebke J, Vermund $\mathrm{SH}$, et al. Prevalence of infectious diseases in Bangladeshi women living adjacent to a truck stand: HIV/ $\mathrm{STD} /$ hepatitis/genital tract infections. Sex Transm Infect 2001, 77: 344-50.

32. Kim WR, Flamm SL, Di Bisceglie AM, Bondenheimer HC. Public Policy Committee of the American Association for the Study of Liver Disease. Serum activity of alanine aminotransferase (ALT) as an indicator of health and disease. Hepatology 2008; 47: 1363-1373.

33. Puoti C, Magrini A, Stati T, Rigato P, Montagnese F, Rossi P, et al. Clinical, histological, and virological features of hepatitis $\mathrm{C}$ virus carriers with persistently normal or abnormal alanine transaminase levels. Hepatology 1997; 26: $1393-8$.

34. Wong VW, Wong GL, Tsang SW, Hui AY, Chan AW, Choi $\mathrm{PC}$, et al. Metabolic and histological features of nonalcoholic fatty liver disease patients with different serum alanine aminotransferase levels. Aliment Pharmacol Ther 2009; 29: 387-96.

35. Park JY, Park YN, Kim DY, Paik YH, Lee KS, Moon BS, et al. High prevalence of significant histology in asymptomatic chronic hepatitis B patients with genotype $\mathrm{C}$ and high serum HBV DNA levels. J Viral Hepat 2008; 15: 615-21.

36. Kumar M, Sarin SK, Hissar S, Pande C, Sakhuja P, Sharma $\mathrm{BC}$, et al. Virologic and histologic features of chronic hepatitis B virus-infected asymptomatic patients with persistently normal ALT. Gastroenterology 2008; 134: 1376-84.

37. Chang Y, Ryu S, Sung E, Jang Y. Higher concentrations of alanine aminotransferase within the reference interval predict nonalcoholic fatty liver disease. Clin Chem 2007; 53: 686-92. 